\title{
Uso da gamificação nos anos iniciais do ensino fundamental brasileiro
}

\author{
Geovania Cezana Araujo Cunha ${ }^{1}$, Luciana Pelissari Barraqui ${ }^{1}$, Sergio Antônio \\ Andrade de Freitas ${ }^{2}$ \\ ${ }^{1}$ Escola Municipal do Ensino Fundamenta Éber Louzada Zippinotti \\ Rua Natalina Daher Carneiro, 815, Jardim da Penha, Vitória - ES- Brasil \\ ${ }^{2}$ Faculdade UnB Gama - Universidade de Brasília (UnB), \\ Area Especial Industria Proj. A, Gama - Brasília - DF - Brasil. \\ geovaniacezana@hotmail.com, lucianapelissaril@gmail.com, \\ Sergiofreitaseunb.br
}

\section{Introdução}

Este artigo apresenta uma pesquisa exploratória na verificação da viabilidade do uso da gamificação nos anos iniciais do ensino fundamental brasileiro. Considerando a aptidão das novas gerações na utilização das ferramentas e dispositivos digitais $[2,5,6]$ e a falta de estudos em gamificação no ensino fundamental [1], esta pesquisa avaliou o quanto a gamificação pode ser usada em sala de aula e se produz motivação nos estudantes. Foram realizadas experimentações e observações do uso da gamificação em alunos do $2^{\circ}$ ano do ensino fundamental. $\mathrm{O}$ experimento foi realizado semanalmente com aulas gamificadas, em duas turmas diferentes de uma mesma escola, com professores diferentes, conteúdos iguais e no mesmo período de tempo. A metodologia de análise dos dados utilizou modelos estatísticos em conjunto com o algoritmo de recuperação de dados Apriori [8].

A contribuição deste trabalho é na avaliação do impacto do uso da gamificação na educação, em especial, nos anos iniciais.

A maioria dos trabalhos apresentados nesta área relatam experiências focadas no ensino médio ou superior [1,6,5], carecendo de um maior aprofundamento de estudo nas crianças de 7 a 9 anos [1].

A aplicação da pesquisa aqui realizada é relevante para a melhoria das práticas educacionais pautadas na utilização da gamificação e dos jogos. Entender como a motivação é obtida a partir de uma determinada gamificação e dos seus elementos associados permite ao professor identificar se (e como) as estratégias da gamificação produzem engajamento nas turmas de anos iniciais.

\section{Trabalhos Relacionados}

Figueiredo et al [6] e Borges et al [5] apresentam uma revisão da área de gamificação no Brasil. Caponetto et al [1] apresentam uma revisão da área fora do Brasil. As revisões apresentadas demonstram que pouco estudo tem sido feito sobre o emprego da gamificação no ensino fundamental. 
VI Congresso Brasileiro de Informática na Educação (CBIE 2017)

Anais do XXVIII Simpósio Brasileiro de Informática na Educação (SBIE 2017)

Nicholson [3] e Mora [4] apresentam uma série de frameworks para gamificação com uma vasta gama de áreas de utilização. Entretanto nenhum deles faz diferenciações e caracterizações sobre o público alvo a ser utilizado na gamificação.

\section{Metodologia}

A partir da revisão da literatura, foi criado um espaço gamificado para alunos do $2^{\circ}$ ano fundamental $[3,7]$. O espaço foi construído a partir da aplicação de um processo de construção de gamificação em quatro passos:

Passo 1 - identificação do objeto a ser gamificado. Foi identificado que a aprendizagem do aluno é o objetivo da gamificação a ser construída.

Passo 2 - identificação do perfil do público alvo. O perfil do estudante foi identificado a partir da experiência dos professores.

Passo 3 - projeto de gamificação. Foi escolhido o framework Octalysis [8] como modelo base para projetar a gamificação a ser construída.

Passo 4 - seleção do cenário para implementação. Foi escolhido um cenário que permitiu a criação de um jogo de sala de aula denominado GE (grupo de estudo). O jogo contemplou as técnicas de jogos previstas no projeto (passo 3).

A fim de verificar o quanto a gamificação produziria motivação/engajamento, foi idealizado um questionário de aplicação indireta, que foi respondido em todas as aulas gamificadas. O contexto da experimentação foi assim definido:

1. Foram utilizadas duas turmas $(\mathrm{A}, \mathrm{B})$ de $2^{\circ}$ ano. Cada turma teve um professor diferente.

2. As duas turmas tiveram o mesmo conteúdo gamificado.

3. Os questionários foram aplicados de forma individual em cada turma.

4. Foi elaborada uma metodologia de refinamento das respostas dos questionários, a partir da interação do professor com a turma durante a coleta de dados.

\section{Resultados}

O uso da gamificação fora do mundo dos jogos influencia o comportamento e envolve os estudantes de forma significativa e motivadora, conduz a uma aproximação com o que ocorre nos games e o modo de como os indivíduos inseridos nesta cultura está mais acostumados a interagir com os problemas e a resolvê-los construindo seus conhecimentos.

A gamificação promove contribuições importantes de como intervir em problemas de aprendizagens, motivação e engajamento dos estudantes em um ensino lúdico e atrativo. As estratégias gamificadas, ativam as motivações para tornar o ensino uma experiência desafiadora de forma a intervir na realidade escolar, envolvendo respectivamente os seus autores como protagonista do processo ensino aprendizagem. Com estratégias gamificadas, aplicadas como ferramentas valiosas para criar experiências significativas no ensino aprendizagem que podem contribuir de forma positiva na formação do cidadão. 
A partir de práticas pedagógicas com estratégias gamificadas, foi alcançado o engajamento dos estudantes dos anos iniciais no processo de ensino aprendizagem, com o uso de elementos lúdicos de jogos, a aprendizagem se desenvolveu de forma agradável e eficaz, com velocidade no processo de mudança de comportamento e aquisição de novos conhecimentos. Aprender jogando é a maneira mais prazerosa e atualizada de ensinar. A gamificação na sala de aula concede a escola uma possibilidade de se recriar.

As aulas que foram gamificadas ocorreram num contexto de construção do conhecimento, potencializando a participação e a motivação dos alunos, de forma com que a aprendizagem do conteúdo ou a habilidade embutida no programa curricular fosse alcançada através de um fazer lúdico, utilizando os elementos, linguagem, estética e mecanismo de games na execução de tarefas propostas em sala de aula de forma divertida e motivadora.

Os dados coletados foram analisados por ferramentas estatísticas (R), bem como foi utilizado o algoritmo Apriori para identificação das regras de correlação dos itens avaliados nos questionários. Os resultados evidenciaram uma forte relação entre a gamificação realizada e a motivação dos alunos, uma diferenciação de percepção entre as aulas que foram gamificadas com as demais aulas e, por fim, a melhoria da aprendizagem em um modelo educacional, menos autoritário, mais colaborativo e interativo.

\section{Referências}

[1] Caponetto, I. et al. Gamification and education: A literature review. Proceedings of the 8th European Conference on Games Based Learning. 2014.

[2] Deterding, S. et al. From game design elements to gamefulness: Defining "Gamification". Proceedings from MindTrek '11. Tampere, Finland: ACM, 2011.

[3] Zichermann, G.; Cunningham, C. Gamification by Design: Implementing Game Mechanics in Web and Mobile Apps. Sebastopol, CA: O'Reilly Media, 2011.

[4] Nicholson, S. A User-Centered Theoretical Framework for Meaningful Gamification. Proceedings of Games+Learning+Society 8.0, Madison, WI, 2012.

[5] Borges, S. et al. (2013). Gamificação Aplicada à Educação: Um Mapeamento Sistemático. Anais do XXIV Simpósio Brasileiro de Informática na Educação, 2013.

[6] Figueiredo, M., Paz, T., \& Junqueira, E. Gamificação e educação: um estado da arte das pesquisas realizadas no Brasil. Anais dos Workshops do IV Congresso Brasileiro de Informática na Educação, 2015.

[7] Chou, Y.-k. Actionable Gamification: Beyond Points, Badges, and Leaderboards. Leanpub, 2015.

[8] Baker, R. et al. Mineração de dados educacionais; oportunidades para o Brasil. Revista Brasileira de Informática na Educação, 19(2):3-11, 2011. 